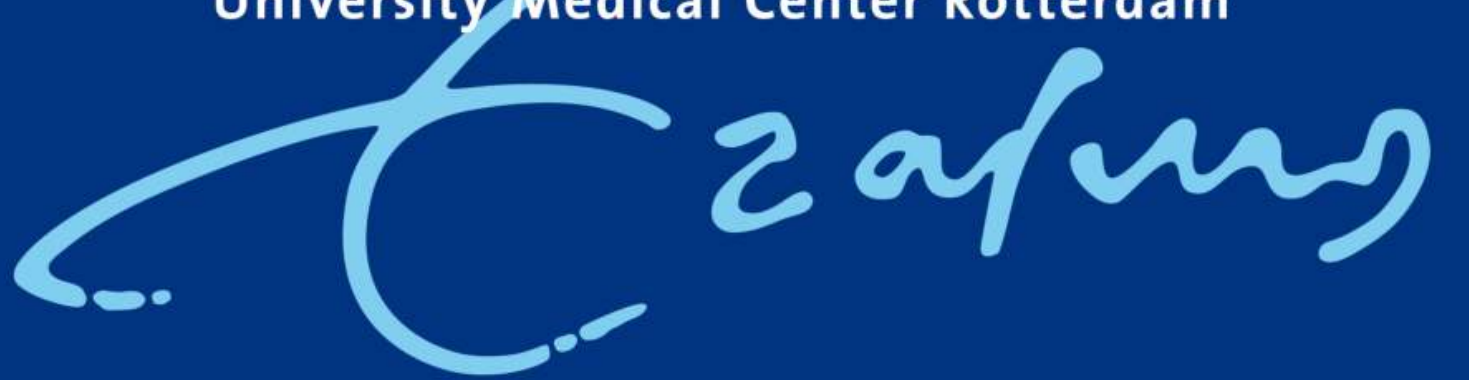

\title{
INCREASING CLEARANCE WITH AGE AND GOOD ORAL BIOAVAILABILITY OF DOXAPRAM IN PRETERM INFANTS: A POPULATION PHARMACOKINETIC MODEL
}

R.B. Flint ${ }^{1,2,3}$, S.H.P. Simons ${ }^{1}$, P. Andriessen ${ }^{4}$, P. Degreauwe ${ }^{5}$, K.D. Liem ${ }^{6}$, I.K.M. Reiss ${ }^{1}$, A.G.J. Engbers ${ }^{7}$, B.C.P. Koch ${ }^{3}$, R. ${\text { de } \text { Groot }^{8} \text {, D.M. Burger }}^{2}$, C.A.J. Knibbe ${ }^{1,7,9}$, S. Völler7 \& DINO research group

1. Department of Paediatrics, Division of Neonatology, Erasmus University Medical Center - Sophia Children's Hospitial, Rotterdam, The Netherlands. 2. Department of Pharmacy and Radboud Institute of Health Sciences (RIHS), Radboudum

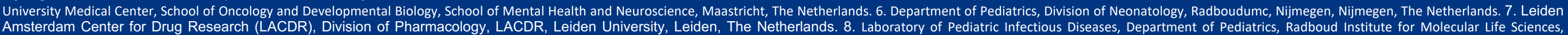

\section{BACKGROUND}

Doxapram is used in preterm infants for treatment of apnea of prematurity. Due to limited pharmacokinetic data, doxapram dosing in preterm neonates is based on bodyweight.

\section{AIM}

To describe the population pharmacokinetics of doxapram and its active metabolite ketodoxapram in preterm neonates with apnea of prematurity.

\section{METHODS}

- 75 patients with apnea despite caffeine

- 302 plasma concentrations doxapram and keto-doxapram

- Covariates: birthweight, actual bodyweight, gestational age, postnatal age, postmenstrual age and gender.

Table 1. Patient characteristics

\begin{tabular}{|l|c|c|}
\hline & Median & (range) \\
\hline Gestational age (weeks) & 25.9 & $(23.9-29.4)$ \\
\hline Gender (Male / Female) & $47 / 28$ & \\
\hline Birthweight (kg) & 0.82 & $(0.39-1.29)$ \\
\hline Postnatal age at start (days) & 17 & $(1-52)$ \\
\hline Actual bodyweight start (kg) & 0.95 & $(0.48-1.61)$ \\
\hline
\end{tabular}

\section{RESULTS}

- 2-compartment model for doxapram as well as for keto-doxapram

- Total clearance (CL) of doxapram was 0.76 $\mathrm{L} / \mathrm{h} / \mathrm{kg}$

- Doxapram clearance and conversion to ketodoxapram increased with gestational and postnatal age

- $15 \%$ of doxapram was converted into ketodoxapram

- For a neonate with GA 25.6 weeks at PNA 29 days; T1/2 of doxapram was 1.4 hours, and T1/2 of keto-doxapram 2.7 hours

- Oral bioavailability was $74 \%$

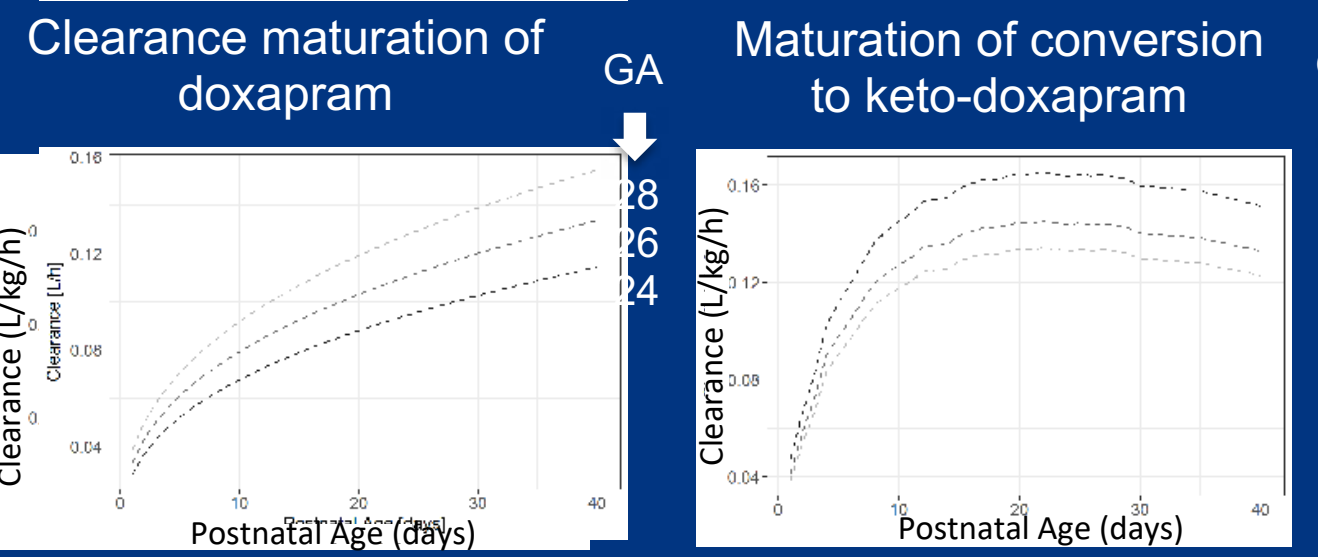

\section{CONCLUSION}

Preterm infants with the lowest GA and PNA have a higher exposure to doxapram and keto-doxapram based on a relatively low CL compared to newborns at older ages when dosed per kg bodyweight.

Doses should be increased with higher GA and increasing PNA. In case of switch to oral therapy a $33 \%$ increase in dose is required to reach similar plasma concentrations.

Table 2. IV doxapram dosages for equal exposure ( $\mathrm{mg} / \mathrm{kg} / \mathrm{h})$

\begin{tabular}{|c|c|c|c|}
\hline $\begin{array}{l}\text { GA } \\
\text { (weeks) }\end{array}$ & $\begin{aligned} & \text { PNA } \\
< & 9 \text { days }\end{aligned}$ & $\begin{array}{c}\text { PNA } \\
10-15 \text { days }\end{array}$ & $\begin{array}{c}\text { PNA } \\
>15 \text { days }\end{array}$ \\
\hline$<26$ & 0.6 & 0.9 & 1.2 \\
\hline $26-27$ & 0.8 & 1.2 & 1.6 \\
\hline $28-29$ & 1.0 & 1.5 & 2.0 \\
\hline
\end{tabular}

CURRENT dosing regimen with one dosage per kg bodyweight: $2.5 \mathrm{mg} / \mathrm{kg}$ bolus dose followed by continuous IV infusion of $2 \mathrm{mg} / \mathrm{kg} / \mathrm{h}$



PROPOSED dosing regimen: $2.5 \mathrm{mg} / \mathrm{kg}$ bolus dose followed by continuous IV dosing according to table 2

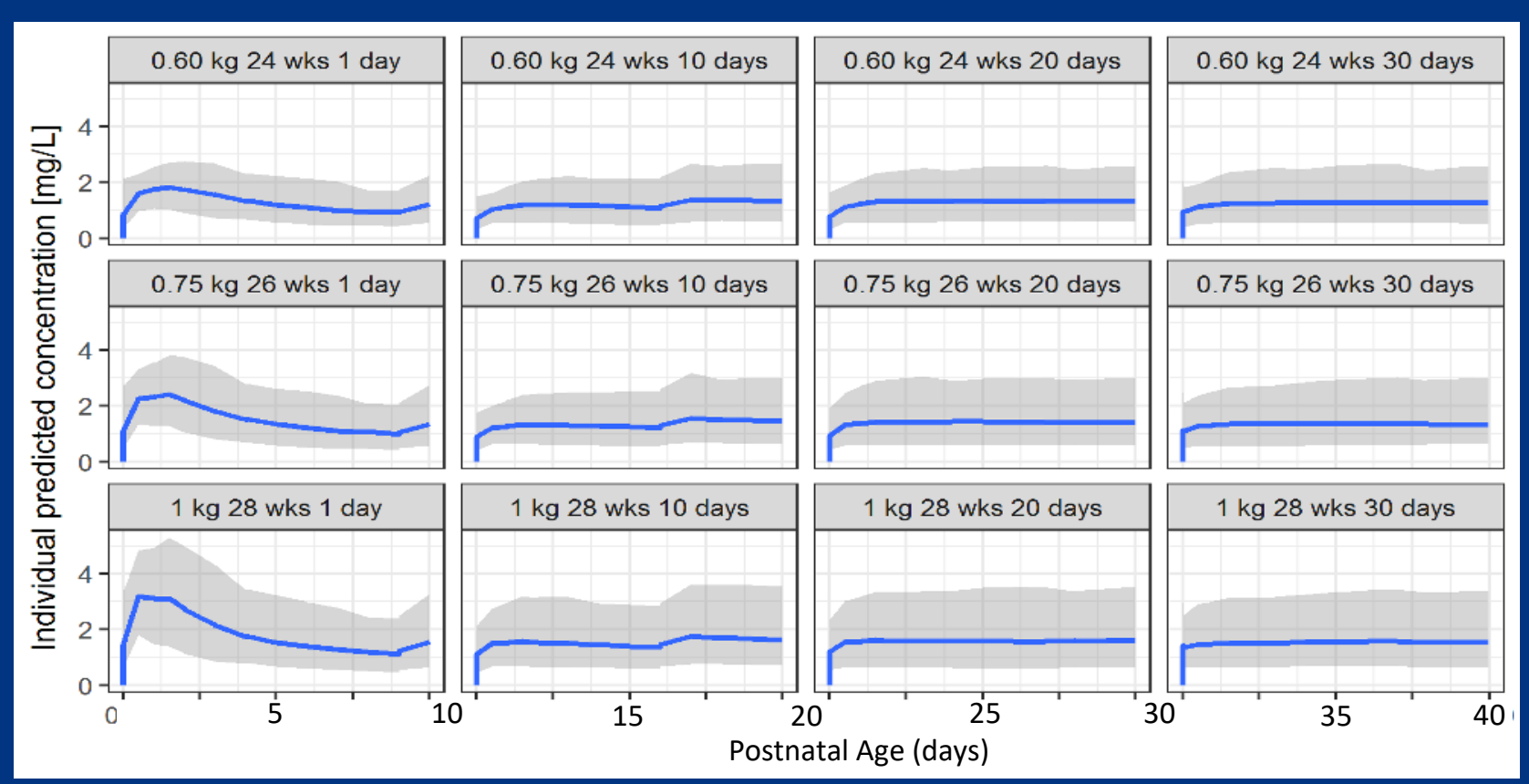

